\title{
LIQUID DISTRIBUTION IMAGES ON STRUCTURED PACKING BY X-RAY COMPUTED TOMOGRAPHY
}

\author{
P. Marchot, D. Toye, A-M. Pelsser, M. Crine, G. L'Homme \\ Laboratoires de Génie Chimique, B6, Université de Liège, Liège B4000, Belgium \\ Z. Olujic \\ Laboratory of Process Equipment, Delft University of Technology, 2628CA Delft ,The \\ Netherlands
}

Although the distillation is considered to be the most mature among separation technologies, the understanding of the processes occurring within a distillation column is still inadequate and consequently represents a significant barrier to the further improvement of equipment performance (Adler et al, 1998). In case of packed columns an obvious barrier for development of advanced predictive models is an inadequate knowledge of the sources and the nature of small scale liquid and gas maldistributions in packed beds. This obstacle could be overcome if we could see inside the packed bed during operation, i.e. develop means to adequately image the liquid flow in a packed bed. X-ray computed tomography is well suited for this purpose, since it is a non intrusive technique which offers the opportunity to unravel complex flow textures with a sufficient spatial resolution.

The purpose of this $R \& D$ note is to present results obtained with the structured packing installed in a column with internal diameter of $0.6 \mathrm{~m}$, using air/water system at ambient conditions. Here, we are mainly concerned with the geometric aspect of the problem.

\section{EXPERIMENTAL}

The heart of the experimental set-up is a $2 \mathrm{~m}$ high, $0.6 \mathrm{~m}$ internal diameter column made of polyethylene with a wall thickness of $0.015 \mathrm{~m}$. The corrugated sheet structured packing used in this study was Sulzer Mellapak 250 Y made of polypropylene with element/sheet height of $0.31 \mathrm{~m}$. The thickness of corrugated sheets is $1.2 \mathrm{~mm}$, the corrugation height is $0.013 \mathrm{~m}$, and the corrugation base is $0.026 \mathrm{~m}$. The upper and lower $50 \mathrm{~mm}$ of the sheet are smooth as well as the central part. Two sections in between are rippled and contain a regular pattern of circled and oval holes with a diameter of $6 \mathrm{~mm}$. The height of installed bed consisting of 4 elements of packing was $1.24 \mathrm{~m}$. Each of these elements consists of two semi cylindrical segments tightened together by the wall wiper. Water (up to $0.006 \mathrm{~m} / \mathrm{sec}$ ) was fed at the top using a liquid distributor with 106 drip points $/ \mathrm{m}^{2}$. Air (up to $2 \mathrm{~m} / \mathrm{sec}$ ) was delivered to the bottom of the column by a blower.

\section{Description of the tomograph}

We designed a X-ray tomograph (fig.1) which rotates around a vertical axis giving scans of horizontal sections of a column (Toye et al.1996). A scan is performed by rotating the source and the detectors set continuously at a constant speed over $360^{\circ}$. The rotation is achieved by a dc motor which is carefully controlled to avoid excessive mechanical strains at start up. The source and the detector bank are fixed on two vertical pillars embedded in a rigid metallic structure. They can be moved vertically by two identical helicoidal screws driven by gears mounted on an horizontal axe rotated by a single dc motor. Vertical position accuracy is 0.001 $\mathrm{m}$. The source provides a collimated flat fan beam of $40^{\circ}$ aperture and of $1 \mathrm{~mm}$ thickness. We use a focal area of $0.4 \times 0.4 \mathrm{~mm}$, a current of $4 \mathrm{~mA}$ and we operate at $140 \mathrm{kV}$. The generator is a Baltograph CS160 constant potential which may be operated between 0-160 kV. The 
detector bank is a $1.7 \mathrm{~m}$ long linear array of 1024 photodiodes built by Slumberger. A 0.006 $\mathrm{m}$ lead sheet is fixed at the back of the bank absorbing the direct radiation. The experimental set-up is installed in a dedicated radio protected lab covered by a $0.004 \mathrm{~m}$ lead sheet. During a scan, the detector bank sends 1024 attenuation measures and the angular position every $20 \mathrm{~ms}$ through a RS422 port. Signals are fed to the ram of a PC. A scan takes around $160 \mathrm{~s}$ leading to files of about $10 \mathrm{Mb}$. Cross section images are reconstructed using the linear filtered back projection algorithm. The code is parallelized and runs on a four processor Sun450. Images of the gas liquid solid distribution over a grid of 1024 x 1024 pixels are obtained with a resolution around $1 \mathrm{~mm}$.

\section{Procedure}

Before starting an experiment a blank is realised to set detectors offsets and gains. This setting is valid over a 4 hour period. Reconstructed sections are masked, thresholded and calibrated. Masking is used to remove the column wall image. Noise level is estimated considering the pixels outside of the mask. A threshold corresponding to $90 \%$ of the noise level is applied to the image contained inside the mask. The solid content of the section is obtained by assuming that the maximum pixel value over different scans corresponds to a pixel totally filled by the solid. The dynamic liquid structure is reconstructed by subtracting, before reconstruction, the signals corresponding to the drained column from the signals corresponding to the irrigated column. In order to quantify the dynamic liquid hold-up, we determined experimentally the water adsorption coefficient by scanning water samples of known thickness. Then, we computed the ratio of the incident to the transmitted light on the projection signal, without reconstructing the image.

\section{RESULTS}

\section{Dry packing}

Fig. 2A,B,C,D presents binarized images of four dry sections taken at various heights. From fig. 2A, which shows a full cross section, it may be clearly seen that a packing element is composed of two semi cylindrical segments packed tightly to each other. Figures $2 \mathrm{~B}$ and $2 \mathrm{C}$, which represent a zoom on a square $(0.41 \mathrm{~m} \times 0.41 \mathrm{~m})$ portion of the cross sectional area taken in the same packing element but vertically separated by $0.032 \mathrm{~m}$, indicate variations of the geometrical structure. Discontinuities in fig. 2B result from the presence of circular holes placed at corrugation ridges. More pronounced discontinuities visible in Fig. $2 \mathrm{C}$ result from oval holes placed on corrugation sides. Fig. $2 \mathrm{D}$ presents a very orderly pattern obtained at the position corresponding to the crossings of corrugation sheets. On fig. 2B, 2C, 2D the split between two cylindrical segments, though still present, is more difficult to distinguish.

The average void fraction measured from such images is $88 \%$ which is the value provided by Sulzer. It fluctuates from section to section, for instance on the section corresponding to fig. $2 \mathrm{C}$, the void fraction is $90 \%$.

The 2D autocorrelation function computed on pixel values is used to extract characteristic length from these images (Pratt, 1978). Square images extracted from the cross section are zero padded to 512 pixels. After subtraction of the mean and normalization by the standard deviation, the Fourier transform of the resulting images are computed. The square of their moduli are Fourier inverted then thresholded, leading to a binary image of the 2D autocorrelation function like that shown on fig. 3. The periodic structure of the packing appears clearly and allows to determine the characteristic length. We obtain $d 1=29.5$ pixel and 
$\mathrm{d} 2=39.7$ pixel or $\mathrm{d} 1=25 \mathrm{~mm}$ and $\mathrm{d} 2=34 \mathrm{~mm}$, i.e. a $12.5 \mathrm{~mm}$ corrugation height $(\mathrm{d} 1 / 2)$ and a 24 $\mathrm{mm}$ corrugation base length $\left(\mathrm{d} 2 \times \sin \left(45^{\circ}\right)\right)$, which is close to the real values $(13$ and $26 \mathrm{~mm})$ mentioned earlier.

A closer look into the dry packing structure was taken by performing 18 scans separated vertically by $1 \mathrm{~mm}$. These images are assembled in a 3D data set from which we extract a small volume for visualization. This volume is smoothed by convolution with a 3 pixel wide $3 \mathrm{D}$ box filter. The smoothing makes isosurface determination easier but leads to an artificial increase of the structure thickness. Isosurfaces (surfaces of constant absorption) and isocaps (intersection with the planes delimiting the region of interest) are drawn using Matlab5.3 computing software. Figure 4 represents a $0.018 \mathrm{~m} \times 0.07 \mathrm{~m} \times 0.07 \mathrm{~m}$ volume extracted from the body of a packing element, indicating corrugations with oval holes. The sheets seem to be fused at their contact points because their thickness is overestimated by our rather crude image processing.

\section{Irrigated packing}

Figures 5A,B,C,D illustrate the dynamic liquid holdup distribution in the packing. They are obtained by superimposing the solid packing image in gray and a thresholded liquid hold-up image in blue. Figures 5A and $\mathrm{B}$ represent the liquid distribution pattern as observed in a cross section of the first and second packing element, rotated to each other by $90^{\circ}$, resulting from a point source distributor. Figures $5 \mathrm{C}$ and $5 \mathrm{D}$ represent the same situation for a 'uniform' (106 drip points $/ \mathrm{m}^{2}$ ) initial liquid distribution. A slightly thicker blue line indicates increased liquid buildup, which occurs at the location corresponding to the split between two segments of a packing element. This is the first experimental evidence that this kind of structural deviation, causing a discontinuity in the liquid flow, can be considered as a potential source of liquid maldistribution. The possible adverse effect on the mass transfer efficiency was considered and modeled by Stoter (1993). Obviously, X-ray tomography, by taking into account the bed layout, provides experimental evidence essential for development and validation of liquid distribution models.

On figure 6, we superimpose the image of a scan performed through the liquid jets dripping from the distributor in blue to the image of the flowing liquid in a section of the first element in gray. Some of these jets are not properly reconstructed probably because of their fluctuations during the scan. Flowing liquid films or rivulets are detected notwithstanding their thickness may be less than the pixel size, however their localization cannot be better than the pixel. Flow patterns like those of fig 5 , were already obtained experimentally by liquid collecting (below the bed) techniques (Hoek et al.,1986) and numerically simulated (Olujic, 1997). They give access to the liquid maldistribution at small as well as at large scale. For instance, we measured a strong increase of dynamic liquid holdup at the interface between packing elements. This effect observed by Suess and Spiegel (1992) using the gamma-ray technique, led to a modification of structured packing design (Billingham and Lockett., 1998, Parkinson et al. 1999). Quantitative results about liquid hold-up will be presented in another paper.

We reconstruct 3D sections of the flowing liquid following the same procedure used for the dry packing. Fig 6A,B,C represent a 3D reconstruction's of a small portion of the first packing element situated around $0.08 \mathrm{~m}$ from the top. Fig. 6A shows the dry packing in blue, fig $6 \mathrm{~B}$ the liquid flowing structure within the same volume, using a uniform distributor, in aquamarine. Superimposing $6 \mathrm{~A}$ and $6 \mathrm{~B}$, we obtain $6 \mathrm{C}$. To get a vivid picture, we choose a volume where the irrigation is poor (which occurs only in the upper part of the first packing element). Due to the smoothing process used to draw the isosurfaces, structure thickness is 
increased. This is especially marked for the liquid structure which grows as thick as the solid. Actually, the narrowest smoothing filter we can apply is 3 pixel wide leading nearly inevitably to structures of that thickness. Consequently, it is impossible to ascertain on which side (front or back) of the sheet the liquid is flowing. In spite of their relative geometrical imprecision these pictures are invaluable in small scale maldistribution investigations.

\section{CONCLUSIONS}

X-ray computed tomography is a non intrusive method which provides quantitative information on the small as well as on the large scale liquid maldistribution in any section of a bed consisting of structured packing, essential for development and validation of rigorous predictive models. Very thin flowing liquid structures may be evidenced and visualized using common 3D graphic tools. The possibility to locate high liquid hold-up zones might lead to design modification of present commercial structured packings.

\section{BIBLIOGRAPHY}

Adler, S., Beaver, E., Bryan, P., Rogers, J. E. L., Robinson, S., and C. Russomanno,

"Vision 2020: Separations Roadmap", American Institute of Chemical Engineers, New York, (1998)

Hoek, P.J., Wesselingh, J.A. and F.J. Zuiderweg, "Small Scale and Large Scale Liquid

Maldistribution in Packed Columns", Chem. Eng. Res. Des., 64, 411 (1986)

Billingham, J.F. and M.J. Lockett, "Development of a New Generation of Structured Packings for Distillation", Trans IChemE, 77 (Part A), 583 (1999)

Olujic, Z., "Development of a Complete Simulation Model for Predicting the Hydraulic and Separation Performance of Distillation Columns Equipped with Structured Packing", Chem. Biochem. Eng. Q., 11 (1), 31 (1997)

Parkinson, G. and G. Ondrey, "Packing Towers", Chemical Engineering, 106, n¹3, 39 (1999)

Pratt W.K., Digital Image Processing, J. Wiley, New-York, (1978)

Suess, P. and L. Spiegel, "Hold-up of Mellapak Structured Packings", Chem. Eng. Proc. 31, 119 (1992)

Stoter, C. F., "Modelling of Maldistribution in Structured Packings: from detail to column design", Dissertation, Delft University of Technology, Delft, (1993)

Toye, D., Marchot, P., Crine, M. and G. L'Homme, "Modelling of multiphase flow in packed beds by computer assisted X-ray tomography”, Meas. Sci. Technol., 7 , 436 (1996)

\section{ACKNOWLEDGMENTS}

D.T. is a post-doctoral fellow of the Belgian Fund for Scientific Research (FNRS)

Mellapak $250 \mathrm{Y}$ was graciously provided and tailored to our column by Sulzer AG. 


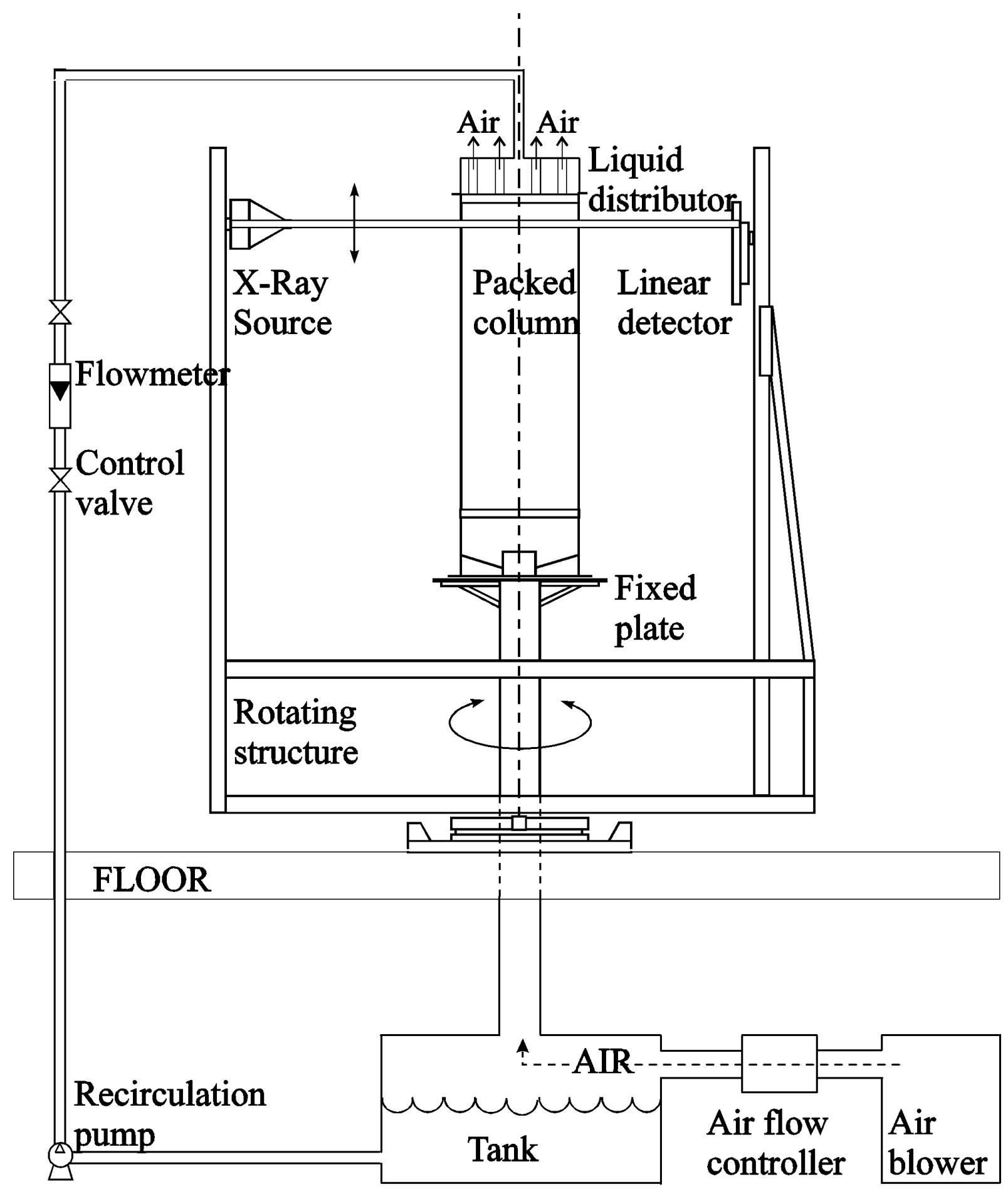



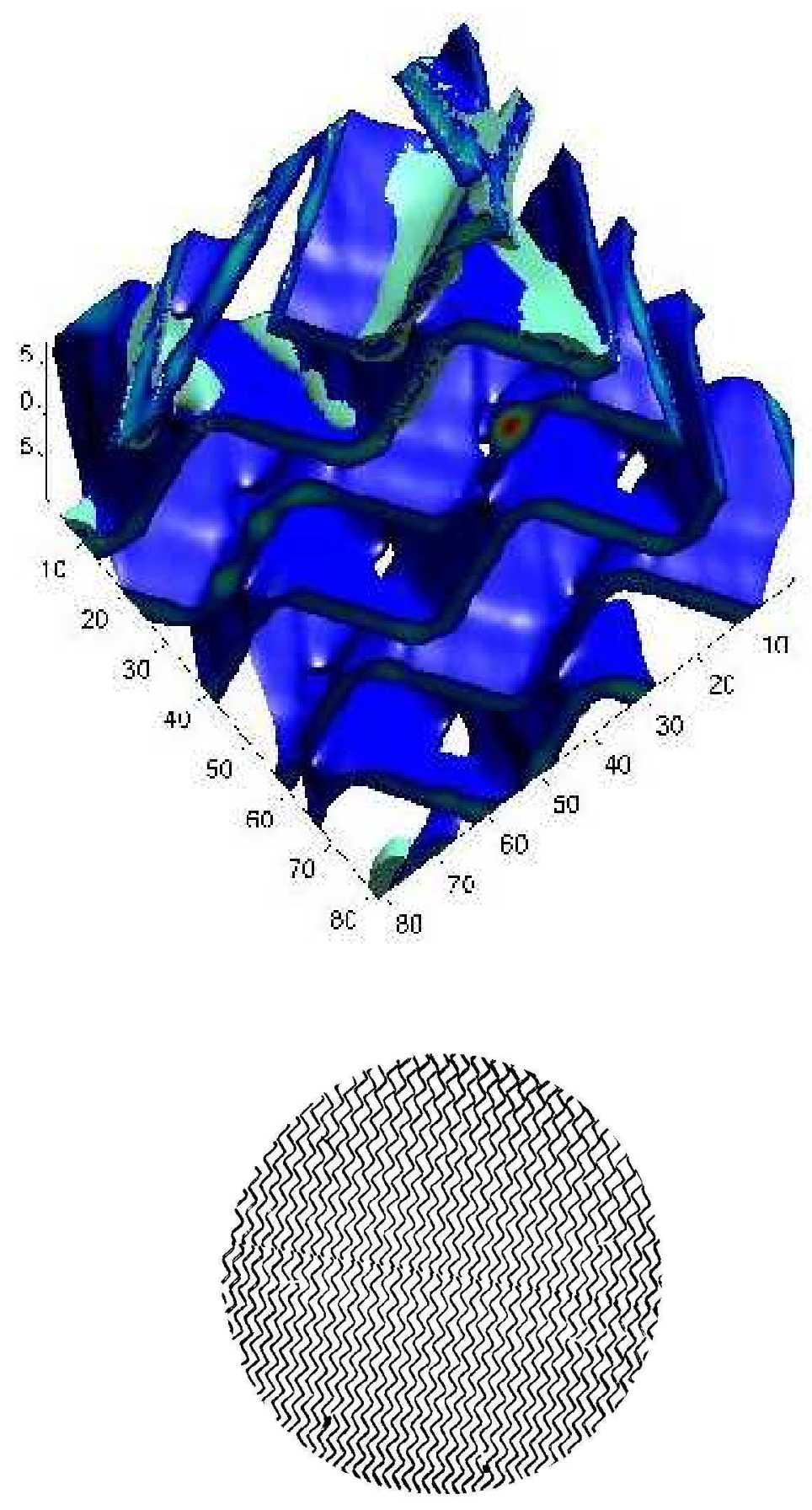

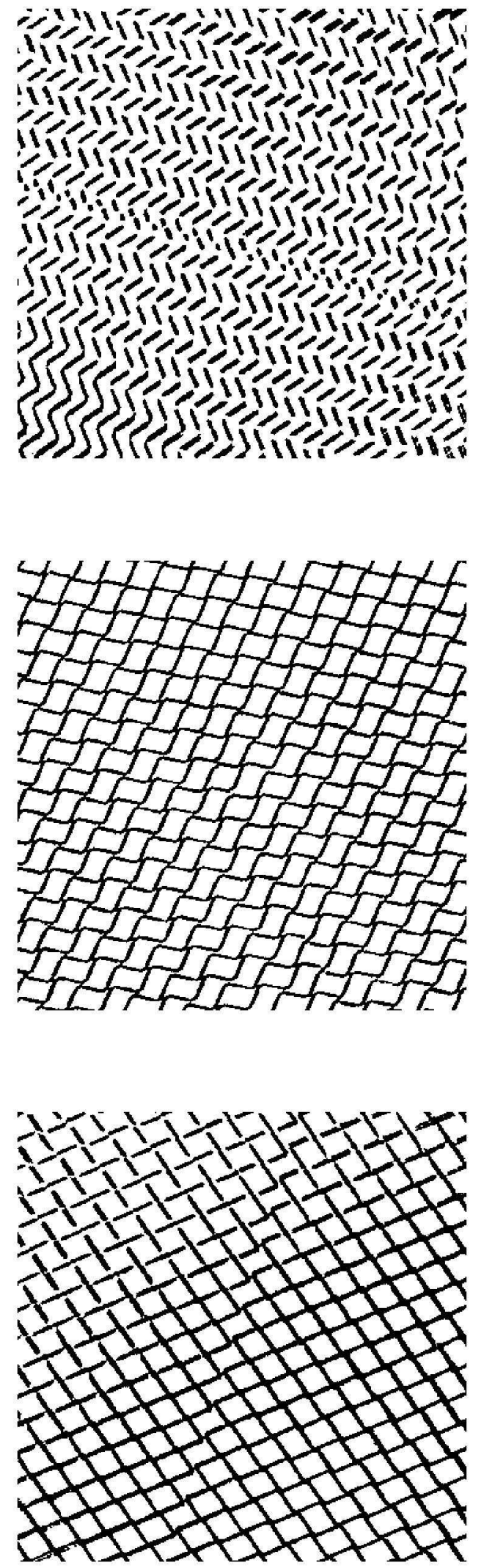

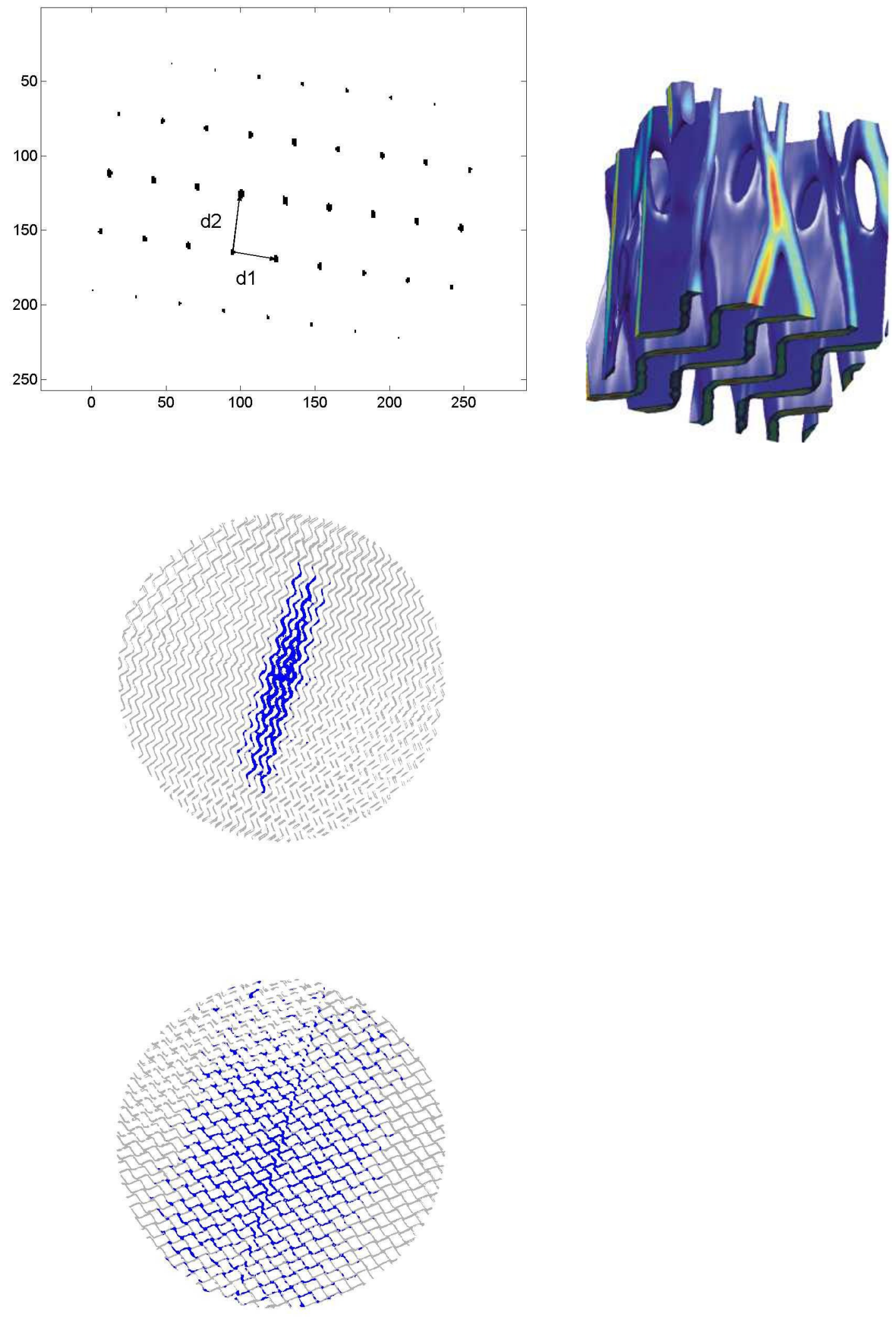

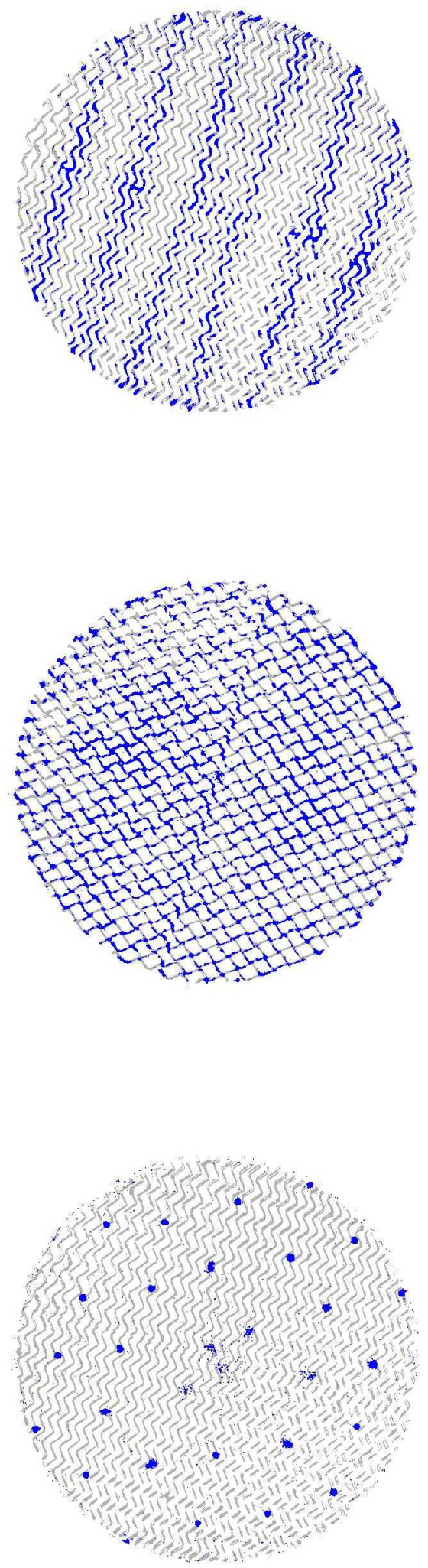

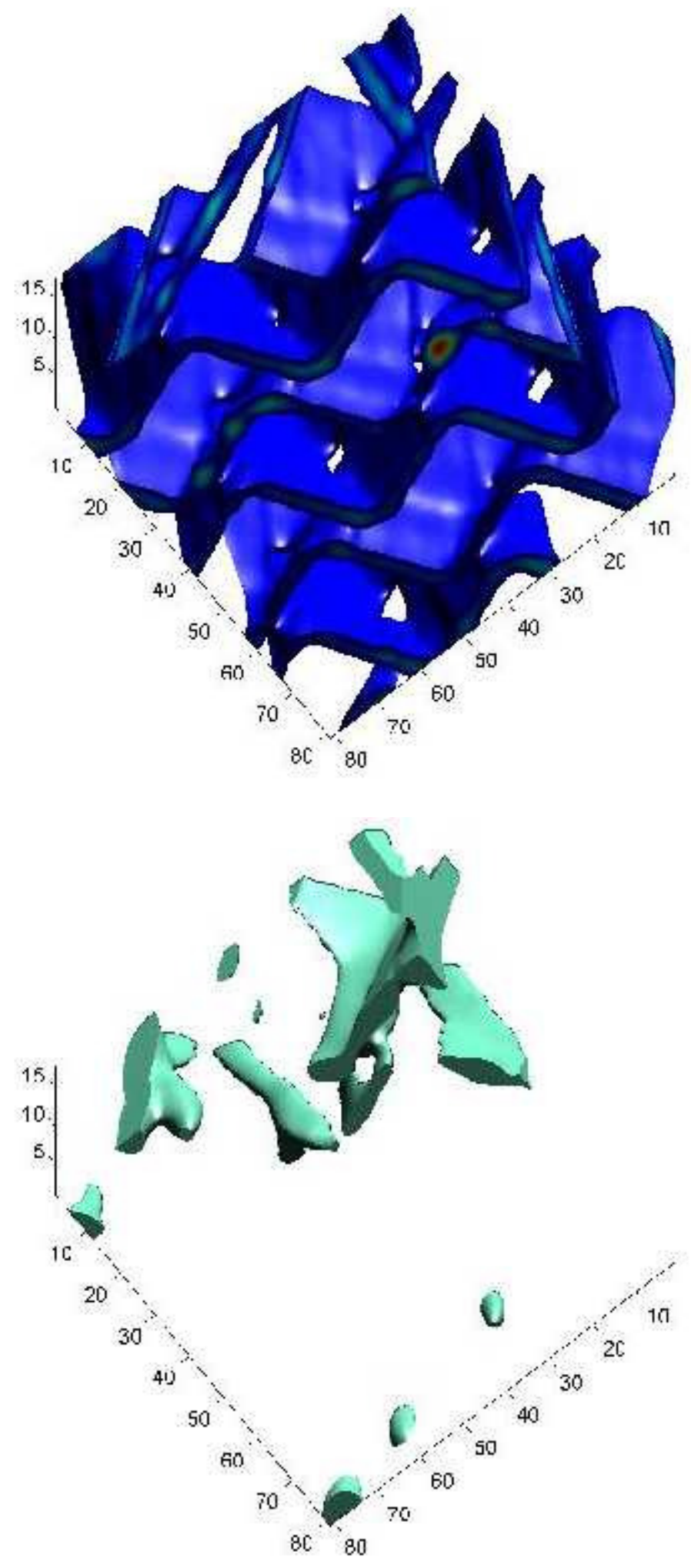